\title{
PROFILE OF SELECTED SENSORIMOTOR SKILLS IN ADOLESCENT POPULATION 6-18 YEARS
}

\author{
Hromčík Adam ${ }^{1}$ \\ Zvonař Martin ${ }^{2 *}$ \\ Balint Gheorghe 3 \\ Bareš Martin ${ }^{4}$ \\ 1,2,4 Masaryk of University, Kamenice 5, 62500, Brno, Czech Republic \\ 3 “Vasile Alecsandri" University of Bacău, 157, Calea Mărășești, 600115, Romania
}

Keywords: Sensorimotor skills, timing, adolescent population

\begin{abstract}
There is a number of studies dealing with the timing of the movement, focusing on the adult population and the population with cerebellar symptoms as a Parkinsson disease or essential tremor (Bareš, 2014, p.67). They try to explain the causes of slowness and their relationship with age or stage of a disease. Our study tries to determine the dynamics of the development of sensorimotor skills, which is responsible for the adolescent brain during ontogenesis and puberty. We are testing only boys from each age 6 to 18. Subjects perform a special test on a PC with a length of about 45 minutes to test their response and timing of movement. Every subject has to deal with a number of tests in which the individual tries to hit a moving target, which appear on the screen at 3 different angles $\left(0^{\circ}, 15^{\circ}\right.$ and $\left.30^{\circ}\right)$ and at different speeds (accelerating, decelerating, constant). This whole at unpredictable intervals by rotation for 45 minutes. Test data will be later evaluated by statistic methods. Predictive motor timing suggests that the cerebellum plays an essential role in integrating incoming visual information with the motor output in a timely manner.
\end{abstract}

\section{Introduction}

Testing the function of the cerebellum in timing the movement was performed at the Neurology Clinic in Brno under the leadership of Professor Martin Bares, which examines the timing of the adult generation and the older population affected by diseases such as Parkinson's disease or essential tremor.

Therefore, we assume a similar methodology, which we applied to youth in order to reveal the course of development processes and their timings and determine the dynamics of the development of sensorimotor skills, for which the cerebellum is responsible in adolescents during ontogeny.

\footnotetext{
*E-mail: zvonar@fsps.muni.cz
} 
Some neuropsycho- logical studies (Meck, 2005, p. 58) showed the importance of the basal ganglia and cerebellum in a wide range of effecting movement (Braitenberg, 1967, pp. 34-37) or direct role in the timing of the movement and its evaluation (Ivry, 2004, pp. 25-27).

There was a series of research (Gibbon, 1997, pp. 23-64; Iacoboni, 2001), which point out the importance of precise timing in sports, while operating vehicles, or at work.

In recent years, are apparent effort to clarify the role played by the basal ganglia and cerebellum in timing and accuracy of responses among people who suffer from some disability so parts of the brain are most Parkinson's disease (Jahanshah, 2010, pp. 727-745; Husárová et al., 2014, pp. 45-46) and, where applicable, other diseases of the cerebellum as essential tremor and ataxia spinocerebellar (Bares, 2010, pp. 124-135). Most recently the study is mapping common factors of early onset of these diseases (Gescheidt, 2016).

As the results of middle-aged populations in these studies have been already measured, we decided to make the same measurement on children aged 6 to 18 years, and determine whether and how they change during the development of motor skills, abilities timing and learning. In this age group had the seasons alternating phases of development and stagnation.

\section{Material and methods}

Testing was conducted using PC software created in LabVIEW 6.1TM environment, National Instruments, Austin, TX, USA. Setting of program task is taken from previous research (Bares, 2007, p. 355). The sample comprised individuals from among schoolchildren. The file structure is as follows: individual years of primary and secondary schools in the file represented by two individuals designated by random selection. Tested are only boys to maintain the selected sample homogeneity and to better compare.

Testing is conducted by the method of data collection through the test on a PC using special software. Data collection will take place through sensorimotor testing methods. Test subjects perform a test on a PC with a length of about 45 minutes to test their response and timing of movement of a number of tests in which the individual tries to hit a moving target, which appear on the screen at different angles and in different speeds (accelerating, decelerating, constant), this whole at unpredictable intervals by rotation for about 45 minutes.

The task consist of the 4 sections (Fig. 1).

The first is training section, where tested pupils gets used to shooting down a moving ball, and also contains a series where the ball changes color from green to red (to be pressed as soon as possible after the change in color) for control the level of the color discrimination.

In the second and third part, which is key for us, is always 6 sets of 54 attempts with 20 seconds long pause. In the last section is again test of the color resolution. Throughout the test the students sitting $60 \mathrm{~cm}$ away from the screen and react with pressing the space bar. 
We compared two groups of children:

1. 9-11 years

2. $15-18$ years

The test is evaluated on the basis of output information from the program used for recording both successful interventions and unsuccessful and also evaluates the size of the premature and delayed reactions.

Test is supplemented by a 10-minute-long questionnaire revealing medical background, level of sports activity, the level of PC gaming and is accompanied by two questionnaires mapping degree of sleepiness and one for the degree of distress. It all parental consent for minor participant.

The protocol for children under 15 years of age has been adapted into a simplified and standardized form contained. In opposite to complete protocol this one have only one questionnaire for the level of sleepiness. All these data are then statistically analyzed.

Hypotesis: The purpose is to compare these results in terms of different years (ages) and find the differences, expose development of speed and gain.

Capture the comprehensive view of the problematics in all age stages.

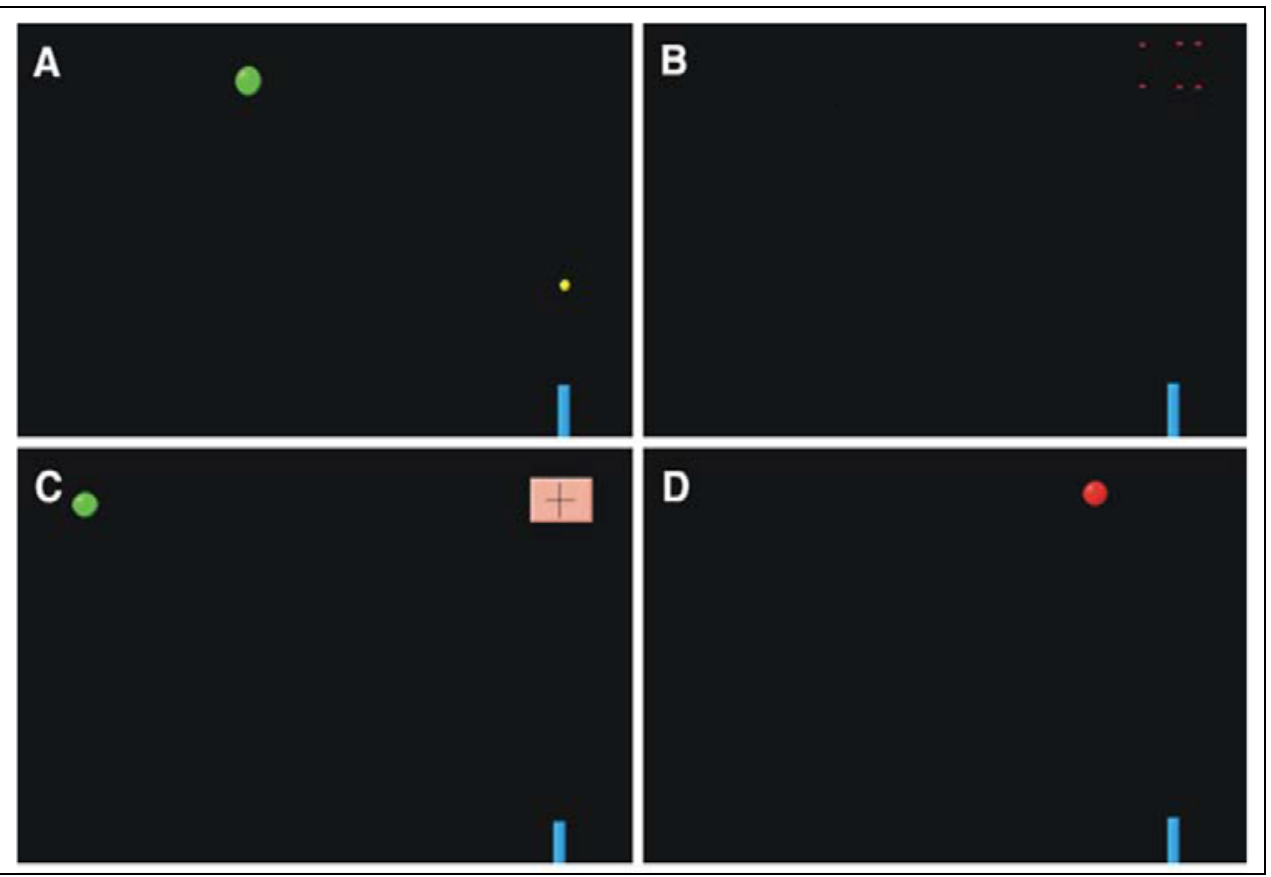

Figure 1. A The main interception task 
The moving green target travelling to the interception zone located in the right upper side of the screen, where the yellow cannon ball will intersect the target. The blue cannon in the lower right corner launched the yellow fireball traveling with constant speed to intercept the moving target. B Target hit. If the subject successfully intercepted the target, both balls exploded (animated with small red points). No animation occurred, if the subject failed to intercept the target. C Control condition 1 (CC 1).

Subjects had to push the fire button at the instant the target ball reached the interception area, now shown in a panel with a crosshair. If subjects were successful, the target exploded. In this case, there was no cannon ball. D Control condition 2 (CC 2).

Target travelled from right to left. At a specific, the target changes color from green to red. Subjects had to push the fire button as soon as target changed the color. (Bareš, 2007)

\section{Results and Discussions}

Currently, we evaluated 21 complete measurements, which have came through the processing in terms of the success of interference in relation to age. There is statistical significant difference between group (9-11) and (15-18) on the significancy level $\alpha=0.05$ ( $p$ value 0.05 ). In the period of 9-11 years there is a fundamental progression in human ontogenesis. This is a sensitive period of development speed and occurs most dynamic shortening reaction times (Měkota, 2005, pp. 61-78)

In publications are often mentioned so-called "movement programs", a certain movement patterns stored in humans. One of the properties of the cerebellum is as well physical memory, which we also examine on the children, because in this period, the most progressive changes happens (Pavlik, 2009, pp. 36-39). By comparison, we chose two groups of children, where are some remarkable changes.

The first mentioned group is children aged 9-11 years, which is going through a "golden age of motorics", and they are at the stage where the basic motor skills go through the development, formed the basic habits of coordinated movements and changes as the ability to speed, power and flexibility.

These changes are partly conditioned by physical activity of students, which could result improve, or get worse, according to the type of stress. Sensitive periods should reflect by valuable activity.

All children we tested in the first group achieve different fluctuating outcomes of the success in interventions, regardless of level of sports and gaming. 
Table 1 Hitrate in first young group

\begin{tabular}{|c|c|}
\hline$\underline{\text { AGE }}$ & $\underline{\text { HITRATE }}$ \\
\hline 9 & $34,3 \%$ \\
\hline 9 & $39,8 \%$ \\
\hline 9 & $36,8 \%$ \\
\hline 9 & $32,4 \%$ \\
\hline 10 & $38,5 \%$ \\
\hline 10 & $32,5 \%$ \\
\hline 10 & $36,6 \%$ \\
\hline 11 & $38,4 \%$ \\
\hline 11 & $39,5 \%$ \\
\hline
\end{tabular}

The second group are high school students who had already taken place puberty. During pubescence (14-16 years) there is significant coordination redevelopment. In raw motorics there is evolution of coordination and the deceleration, especially influence of body growth and changes in leverage ratios of extremities, while in the soft motorics development evolution occurs especially in the interplay of eye - hand (Zvonař \& Duvač, 2011).

Their motoric skills have gone through a significant transformation. There is the transformation and growth of motor skills and the ability to conjugate movements, their differentiation.

Age group is then after the 15 year rebuilding and stabilizing and slowly coming into top motoric phase in the life cycle (from the 20 year of man). The success of this group is clearly influenced by this evolutionary leap.

Table 2 Hitrate in second young group

\begin{tabular}{|c|c|}
\hline$\underline{\text { AGE }}$ & $\underline{\text { HITRATE }}$ \\
\hline 15 & $52,3 \%$ \\
\hline 15 & $55,6 \%$ \\
\hline 15 & $50,7 \%$ \\
\hline 16 & $55,7 \%$ \\
\hline 16 & $42,3 \%$ \\
\hline 17 & $44,9 \%$ \\
\hline 17 & $52,1 \%$ \\
\hline 18 & $55,2 \%$ \\
\hline 18 & $51,7 \%$ \\
\hline
\end{tabular}

It is obvious that both groups differ significantly, which might confirms our hypothesis of a significant adjustment capability for timed movement and 
the accuracy of these moves (interventions).

Soft motoric skills are really at a better level against the younger group, their attention during the test was significantly better, execution quiet and without many distractions.

Other interesting results we expect after comparing with the rest of the age spectrum, which should realistically shows, what impact the development on motoric fluctuations and if we are able to draw a clear trend from the results.

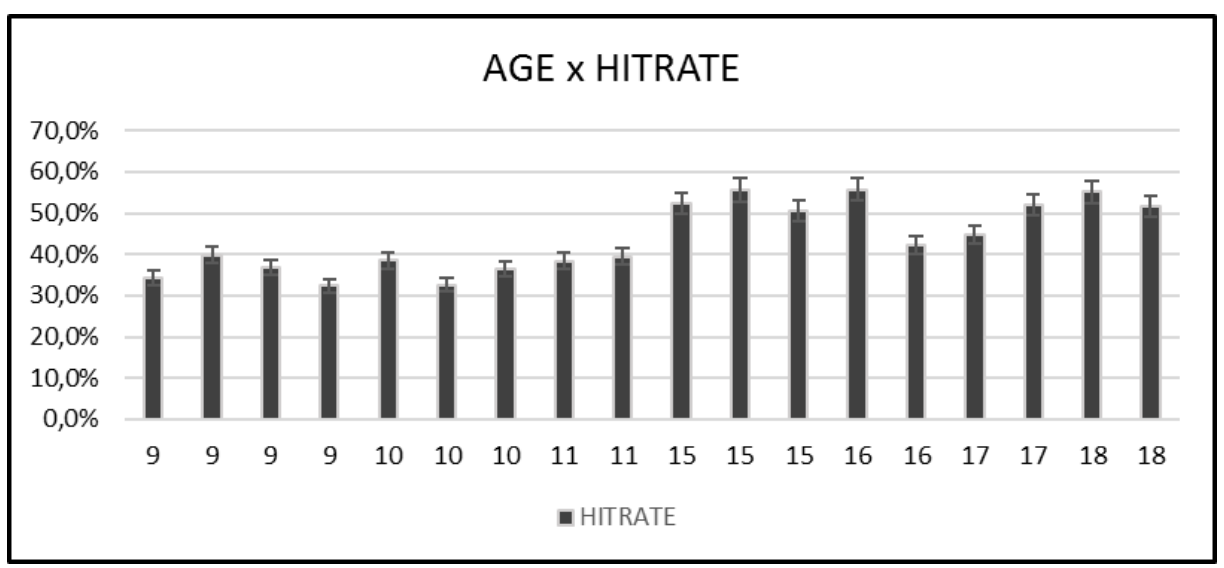

Figure 2. Age vs. hitrate of participant in the test

\section{Conclusions}

In an effort to find and compare the differences we managed clearly description of the fundamental shift in motor development, which will be complete upon completion of the measurements. It will give us a clearer picture of the level of response speed and timing.

Interesting will be mainly continuity build on the results of measurements from adult athletes on the sports faculty in Brno and on the further measurements the whole age range until in the senescence. More complicated statistical methods also reveals differences in the first training section and maybe the possibility of improving the successful intervention during the course of the test, which the older healthy adults measurement doesn't confirmed (Filip, Lošák, Punch, Vanicek, \& Bares, 2016).

For young controls could be due to the early development of motor skills and coordination different situation. In cooperation with Masaryk University in Brno we want to help explain the specifics of sensorimotor timing and time prediction, practically from childhood to old age.

These results can contribute to the early detection of diseases and disorders of the cerebellum and thereby help to create rehabilitation programs or appropriate medications. 


\section{References}

1. BARES, M., LUNGU, O.V., LIU T., WAECHTER, T., GOMEZ, C. M., ASHE, J. (2007). Impaired predictive motor timing in patients with cerebellar disorders, Experimental Brain Research (online). 180 (2), 35565 [cit. 2016-10-14].

2. BARES, M., LUNGU, O.V., HUSÁROVÁ, I., GESCHEIDT, T. (2010). Predictive motor timing performance dissociates between early diseases of the cerebellum and Parkinson's disease. Cerebellum London, England, (online). 9(1), 124-35 [cit. 2016-10-13].

3. BARES, M. (2014). The cerebellum, basal ganglia and motor timing in movement disorders. Behavioral and fMRI study. Clinical Neurophysiology (online). 125 (5), e39 [cit. 2015-10-29];

4. BRAITENBERG, V. (1967). Is the cerebellar cortex a biological clock in the millisecond range? Progress In Brain Research [online]. 25, 334-46 [cit. 2016-10-13];

5. FILIP, P., LOŠÁK, J., KAŠPÁREK, T., VANÍČEK, J., BAREŠ, M. (2016). Neural Network of Predictive Motor Timing in the Context of Gender Differences, Neural Plasticity (online), 2073454 [cit. 2016-1013];

6. GESCHEIDT, T., LOSADA, V. Y., MENŠÍKOVÁ, K., DUŠEK, L., CZEKÓOVÁ, K., MENCLOVÁ, P., \& BAREŠ, M. (2016). Impulse control disorders in patients with young-onset Parkinson's disease: $A$ cross-sectional study seeking associated factors, Basal Ganglia;

7. GIBBON, J., MALAPANI, C., DALE, C.L., GALLISTEL, C. (1997). Toward a neurobiology of temporal cognition: advances and challenges, Current Opinion In Neurobiology (online). 7 (2), 170-84 [cit. 2016-1013];

8. HUSÁROVÁ, I., LUNGU, O.V., MAREČEK, R., MIKL, M., GESCHEIDT, T., KRUPA, P., BAREŠ, M. (2014). Functional imaging of the cerebellum and basal ganglia during predictive motor timing in early Parkinson's disease, Journal Of Neuroimaging: Official Journal Of The American Society Of Neuroimaging (online). 24 (1), 45-53 [cit. 2016-1013];

9. IACOBONI, M. (2001). Playing tennis with the cerebellum, Nature Neuroscience (online). 4(6), 555-6 [cit. 2016-10-13];

10. IVRY R B; SPENCER R M. 2004. The neural representation of time. Current Opinion In Neurobiology (online). 14 (2), 225-32 [cit. 2016-1013];

11. JAHANSHAHI, M., JONES, C.R., ZIJLMANS, J., KATZENSCHLAGER, R., LEE, L., QUINN, N., FRITH, C.D., LEES, A.J. (2010). Dopaminergic modulation of striato-frontal connectivity during motor timing in Parkinson's disease, Brain: A Journal of Neurology (online). 133 (Pt 3), 727-45 [cit. 2016-10-13]; 
12. MECK, W. H. (2005). Introduction: Neuropsychology of timing and time perception, Brain and Cognition (online). 58 (1), 1-8 [cit. 2016-10-12];

13. MEKOTA, K., NOVOSAD J. (2005). Motorické schopnosti, 1. vyd. Olomouc: Univerzita Palackého v Olomouci, Czech Republic;

14. PAVLIK, J. (2010). Vybrané kapitoly z antropomotoriky, 1. Brno: Masarykova univerzita, Czech Republic. 36-39;

15. ZVONǍ̌, M., DUVAČ, I. (2011). Antropomotorika: pro magisterský program tělesná výchova a sport. 1. vyd. Brno: Masarykova univerzita, Czech Republic. 